\title{
ABSORPTION FEATURES IN THE 5-8 MICRON SPECTRA OF PROTOSTARS
}

\author{
A. G. G. M. Tielens, ${ }^{1}$ L. J. Allamandola,${ }^{1}$ J. Bregman, ${ }^{1}$ J. Goebel,${ }^{1}$ L. B. D’Hendecourt, ${ }^{2}$ \\ AND F. C. WITTEBORN ${ }^{1}$ \\ Received 1984 April 2; accepted 1984 June 26
}

\begin{abstract}
High signal-to-noise ratio 5-8 $\mu \mathrm{m}$ spectra of four sources embedded in molecular clouds are presented. All four sources show evidence for the presence of absorption features. The shape of these features changes, however, dramatically from source to source. They range from two relatively narrow bands at 6.0 and $6.8 \mu \mathrm{m}$ in W33A to a broad, shallow feature, which extends from about 5.2 to $7.8 \mu \mathrm{m}$ and shows some structure, in Mon R2-IRS2, BN, and NGC 2264.

The $2-13 \mu \mathrm{m}$ spectra of simple molecules and mixtures of simple molecules have been measured at low temperatures in the laboratory. These spectra are discussed with emphasis on the 5-8 $\mu$ m region. Comparison of the observed spectra with the laboratory spectra leads to the conclusion that the rather narrow 6.0 and 6.8 $\mu \mathrm{m}$ absorption features in $\mathrm{W} 33 \mathrm{~A}$ are largely due to the $\mathrm{OH}$ bending mode in $\mathrm{H}_{2} \mathrm{O}$ and the $\mathrm{CH}$ deformation modes in saturated hydrocarbons, respectively. The much broader, shallower absorption features in the other sources cannot be solely attributed to these molecules.

The implications of the observed differences in the 6.0 and $6.8 \mu \mathrm{m}$ absorption features for interstellar grain chemistry are discussed. W33A type spectra may be consistent with mantle compositions determined largely by grain surface chemistry. Mon R2-IRS2 type spectra imply that much more extensive processing has occurred within the mantle itself, producing a richer chemical mixture. Such processing may be due to UV photolysis.

Subject headings: infrared: spectra - interstellar: grains - interstellar: molecules - stars: pre-main-sequence
\end{abstract}

\section{INTRODUCTION}

One of the most direct ways to study the properties of molecular grain mantles in dense interstellar clouds is by infrared spectroscopy. Broad absorption features appear superposed on the infrared continua of many interstellar sources obscured by dense regions of dust. Because of their spectral width most of these features are attributed to vibrational transitions in solid material (Hagen, Allamandola, and Greenberg 1980; Allamandola 1984). Due to increasing sensitivity and spectral resolution, their number is steadily increasing. They now include features at 2.97, 3.08, 3.4, 4.61, 4.67, 6.0 and $6.8 \mu \mathrm{m}$ (Merrill, Russell, and Soifer 1976; Puetter et al. 1979; Knacke et al. 1982; Lacy et al. 1984).

Spectra at 5-8 $\mu \mathrm{m}$ are a valuable tool for the study of saturated hydrocarbons in interstellar grain mantles. Although such molecules also show absorption bands arising from $\mathrm{CH}$ stretching modes around $3.4 \mu \mathrm{m}$, detection of those bands is hampered by the presence of the extremely strong and broad $\mathrm{OH}$ stretching mode in solid $\mathrm{H}_{2} \mathrm{O}$ at $3.08 \mu \mathrm{m}$. The intensity of this band increases strongly upon complexing (formation of a hydrogen-bonded network) of the $\mathrm{H}_{2} \mathrm{O}$ molecules (van Thiel, Becker, and Pimentel 1957). Its strength increases by as much as a factor of 25 in going from the gas phase to amorphous solid water (Hagen, Tielens, and Greenberg 1981). The strength of the $\mathrm{CH}$ stretching modes remains, however, constant independent of the concentration. Furthermore, complexing of $\mathrm{H}_{2} \mathrm{O}$ with strong bases, such as $\mathrm{NH}_{3}$, will produce a lowfrequency wing (Hagen, Tielens, and Greenberg 1983a) complicating the search for carbon bearing molecules in interstellar

\footnotetext{
${ }^{1}$ NASA/Ames Research Center.

${ }^{2}$ Laboratory Astrophysics Group, Rijksuniversiteit Leiden, The Netherlands.
}

grain mantles in this part of the spectrum even further. The 5-8 $\mu \mathrm{m}$ region, in contrast, is much cleaner. The $\mathrm{OH}$ bending mode in $\mathrm{H}_{2} \mathrm{O}$ neither increases in strength nor broadens severely upon complexing, making detection of the $\mathrm{CH}$ deformation modes around $6.8 \mu \mathrm{m}$ rather straightforward.

Recently the molecular composition of accreting interstellar grain mantles has been calculated numerically. It is thought to consist mainly of the molecules $\mathrm{H}_{2} \mathrm{O}, \mathrm{H}_{2} \mathrm{CO}, \mathrm{CO}, \mathrm{CO}_{2}, \mathrm{~N}_{2}$, $\mathrm{O}_{2}$, and $\mathrm{NH}_{3}$, in varying ratios depending on the physical conditions in the gas phase (Tielens and Hagen 1982; d'Hendecourt 1984). Deuterated forms of these molecules may also be abundant (Tielens 1983). It has been suggested that UV photolysis transforms these simple molecules into more complex ones (Greenberg and Yencha 1973).

This paper reports new 5-8 $\mu \mathrm{m}$ spectra of four sources embedded in molecular clouds (§ II). In $\S$ III we discuss laboratory spectra of simple molecules and mixtures of simple molecules with an emphasis on the 5-8 $\mu \mathrm{m}$ region. The observational results are compared with the laboratory data in $\S$ IV. The implications of the observations on our understanding of interstellar grain surface chemistry are also discussed in $\S$ IV. Section V summarizes the main results.

\section{OBSERVATIONS}

The 5-8 $\mu \mathrm{m}$ spectra were obtained with the Faint Object Grating Spectrometer (FOGS), a 24 detector, LHe-cooled, grating spectrometer (Witteborn and Bregman 1984), during portions of three flights on the Kuiper Airborne Observatory. The $24 \mathrm{Si}$ : Bi detectors ( 23 of which operated) were multiplexed so that each was integrating essentially all the time. The signal level on each one was sampled several times during each extreme of the secondary mirror motion. The signals were digitized and stored in 24 element arrays by a computer on disk 
memory. Wavelength calibration was achieved by obtaining spectra of an on-board blackbody through a polyethylene sample which was, in turn, calibrated against an ammonia cell. The resolution of the FOGS was $0.12 \mu \mathrm{m}$ per channel (or detector, $\lambda / \Delta \lambda \approx 50$ ) in the configuration used for the $\mathrm{KAO}$ flights.

The beam size of the observations is $21^{\prime \prime}$. This is generally much larger than the size of the sources. However, no other bright compact sources were present in the beam. Although $\mathrm{BN}$ is embedded in an infrared reflection nebula, its surface brightness is quite low (Werner, Dinerstein, and Capps 1983). Furthermore, it has been shown that the $3.08 \mu \mathrm{m}$ ice band is also present in the scattered light (Tielens, Werner, and Capps 1984), reducing further the possibility of a significant filling in of absorption features by nebular light.

On the first two flights $\beta$ And and $\alpha$ Tau were observed as standard stars. During the last flight only $\beta$ And was observed. Figure $1 a$ shows the ratio of the spectrum of $\beta$ And to that of $\alpha$ Tau, obtained on the second flight. The atmospheric features in these two spectra cancel to better than $5 \%$, despite the rather large difference in elevation angle between these two objects $\left(35^{\circ}\right.$ vs $\left.65^{\circ}\right)$.

Table 1 summarizes the observations. The sources were selected according to their brightness, the presence of a $3.08 \mu \mathrm{m}$ ice band, and their position in the sky. In this way the three so-called protostars, BN, NGC 2264, and Mon R2-IRS2, and one object, P13S, whose evolutionary status is unknown, were selected. Figure 2 shows the $5-8 \mu \mathrm{m}$ spectra of these sources as well as the previously published spectrum of W33A (Capps, Gillett, and Knacke 1978; Soifer et al. 1979). The spectra of the objects are ratioed against the standard star, closest in elevation to it. Because the water vapor radiometers did not work during these flights, a more detailed correction for atmospheric transmission is impossible. We feel confident that our spectra are correct, however, for two reasons. First, the ratio of $\beta$ And to $\alpha$ Tau does not show atmospheric features above the $5 \%$ level. The difference in elevation angle for the two standards is much larger than for any of the protostar-standard combinations used. Second, none of the corrected spectra shows evidence for spurious features due to incomplete or overcorrection of atmospheric features. For Mon R2-IRS2 the statistical error is about 5\%. For BN and NGC 2264 the statistical errors are about the size of the dots. For P13S a representative errorbar is shown.

Most of our objects are invisible and guiding was done by offsetting from a nearby, bright, visible star. BN, NGC 2264 and Mon R2-IRS2 are bright infrared sources, and it was possible to peak up in the infrared on these sources. While misguiding on the object will cause a slight tilt of the spectrum, no

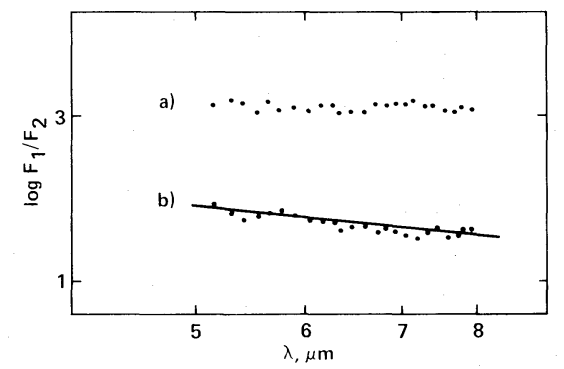

FIG. 1. - (a) The ratio of the observed spectrum of $\alpha$ Tau to that of $\beta$ And (arbitrary units). (b) The ratio of the spectrum of $\mu$ Cep, intentionally misguided by $7^{\prime \prime}$, to that of $\mu$ Cep correctly guided (arbitrary units).
TABLE 1

\begin{tabular}{|c|c|c|}
\hline Object & $\begin{array}{l}\text { Date } \\
(1983)\end{array}$ & $\begin{array}{l}\text { Integration Time } \\
\text { (minutes) }\end{array}$ \\
\hline \multirow[t]{2}{*}{$\mathrm{BN}, \ldots \ldots \ldots \ldots \ldots \ldots \ldots \ldots \ldots \ldots$} & Nov 28 & 8 \\
\hline & Nov 30 & 12 \\
\hline Mon R2-IRS2 & Dec 1 & 15 \\
\hline NGC $2264 \ldots$. & Dec 1 & 12 \\
\hline \multirow[t]{2}{*}{$\mathrm{P} 13 \mathrm{~S} \ldots \ldots$} & Nov 30 & 36 \\
\hline & Dec 1 & 35 \\
\hline \multirow[t]{2}{*}{$\alpha$ Tau } & Nov 28 & 8 \\
\hline & Nov 30 & 10 \\
\hline \multirow[t]{3}{*}{$\beta$ And } & Nov 28 & 11 \\
\hline & Nov 30 & 12 \\
\hline & Dec 1 & 12 \\
\hline
\end{tabular}

spurious features will be generated as shown by Figure $1 b$ where the ratio of a spectrum of $\mu \mathrm{Cep}$, intentionally misguided by 7 ", to a spectrum of $\mu \mathrm{Cep}$, correctly guided is presented. The scatter in the data points around the full drawn line is due to statistical noise. The tilt in the ratio is about $20 \%$. The flux level can increase or decrease with increasing $\lambda$. Judging from the values of the intermediate integration pairs, it is estimated that the guiding was better than $3^{\prime \prime}$ on each of the protostars. Consequently this source of systematic error can be neglected.

In order to be able to judge the continuum level $2-4 \mu \mathrm{m}$ and 8-13 $\mu \mathrm{m}$ spectra gathered from the literature are also shown in Figure 2. The slight mismatches in continua between these spectra and the 5-8 $\mu \mathrm{m}$ spectra are probably due to differences in absolute calibration or beam size.

The absolute flux level of the 5-8 $\mu \mathrm{m}$ spectra of $\mathrm{BN}$ and NGC 2264 are in good agreement with previously published spectra in this wavelength region (Russell, Soifer, and Puetter 1977; Willner et al. 1982). A detailed comparison shows many differences, however. The earlier spectra show structure which is not present in our data. Also the general shapes of those spectra are somewhat different from the spectra presented here. These differences, larger then the quoted statistical errors, probably represent systematic errors inherent in the earlier observations. Those were made with a CVF spectrometer in which each frequency is observed sequentially. A brief change in transmission or variations in pointing can produce spurious features which are not averaged out unless numerous scans are obtained. Of the several advantages inherent in a multielement system such as the FOGS, two are particularly important in this respect: (1) Using a multi-detector array improves the sensitivity and consequently decreases the integration time; and (2) all spectral points are observed simultaneously, thus eliminating an important source of spurious spectral features.

\section{LABORATORY STUDIES}

\section{a) Laboratory Procedures}

Since details of the experimental technique have been described elsewhere (Hagen, Allamandola, and Greenberg 1979; Hagen, Tielens, and Greenberg 1981) only a brief review will be presented here. Gas mixtures are slowly condensed onto a cold $(10 \mathrm{~K}) \mathrm{CsI}$ window. The deposition rate and ultimate sample thickness $(0.1-1.5 \mu \mathrm{m})$ are measured with a laser interference technique. The deposition rate (sample growth rate) is 3 $\mu \mathrm{m} \mathrm{hr} r^{-1}$ or less. The CsI window is cooled to $10 \mathrm{~K}$ by a closed cycle helium refrigerator (Air Products Displex CSW-202A). Infrared absorption spectra from 4000 to $500 \mathrm{~cm}^{-1}$ of these 


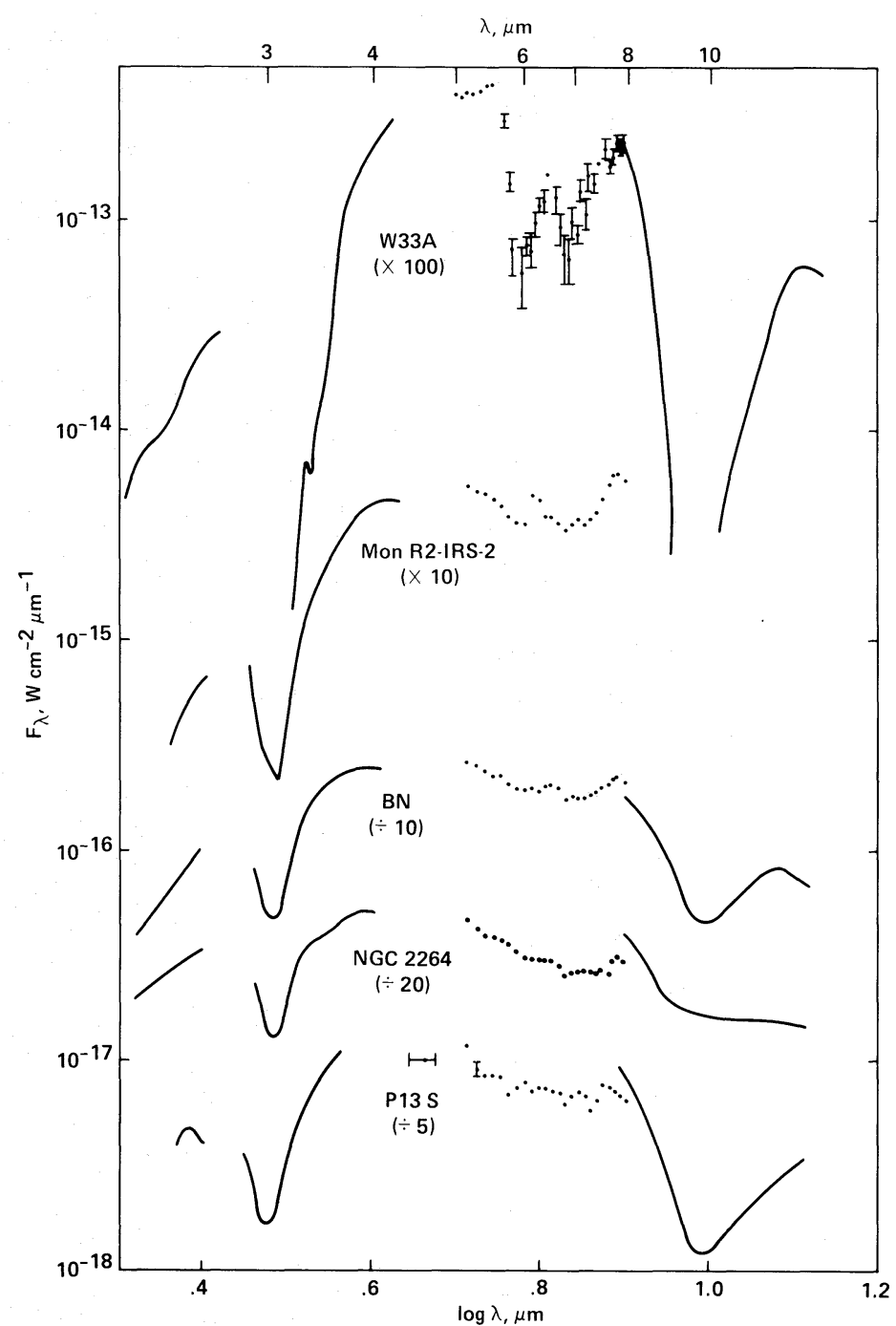

FIG. 2.-The near-infrared spectra of compact sources in molecular clouds. The 2-4 and 8-13 $\mu \mathrm{m}$ spectra are taken from Merrill et al. (1976), Capps et al. (1978), Joyce and Simon (1982), and Cohen et al. (1983). The 5-8 $\mu \mathrm{m}$ spectrum of W33A is taken from Soifer et al. (1979).

samples at $2 \mathrm{~cm}^{-1}$ resolution are obtained with a Michelson interferometer (Digilab FTS $15 \mathrm{~B} / \mathrm{D}$ ) using slightly modified optics. Some samples are exposed to UV radiation from a hydrogen discharge lamp, equipped with $\mathrm{MgF}_{2}$ optics. This will alter the composition of the mixtures. These UV-irradiated mixtures are then allowed to warm up slowly. At a few intermediate temperatures, this warm-up process is interrupted to measure another infrared spectrum.

\section{b) Laboratory Results}

The possible vibrational modes of a characteristic group within a molecule include stretching, scissoring, wagging, twisting, rocking, and torsional motions between the various atoms. The absorptions due to these motions generally occur in a narrow frequency region. For example, the $\mathrm{CH}$ stretch in methyl $\left(-\mathrm{CH}_{3}\right)$ or methylene $\left(-\mathrm{CH}_{2}-\right)$ groups occur between $2960-2850 \mathrm{~cm}^{-1}$ (3.38-3.51 $\mu \mathrm{m}$; Bellamy 1960). Small shifts in the peak frequency can occur because of coupling of different modes within the molecule. Larger shifts will occur when the characteristic group can form hydrogen bonds. For example, the $\mathrm{OH}$ stretch in isolated $\mathrm{H}_{2} \mathrm{O}$ occurs around 3700 $\mathrm{cm}^{-1}(2.7 \mu \mathrm{m})$, while in ice it occurs around $3250 \mathrm{~cm}^{-1}(3.08$ $\mu \mathrm{m})$. Coupling of a mode with an overtone or a combination band within the same molecule (Fermi resonance) may give rise to frequency shifts and/or intensity enhancement. Within a mixture such interactions may also occur with neighboring molecules. A more detailed description of the infrared spectroscopic characteristics of molecular ices is given by Allamandola (1984).

In the remainder of this section we will discuss the 5-8 $\mu \mathrm{m}$ spectra of simple molecules and mixtures of a few simple molecules. A more detailed discussion, including the complete spectra, the derivation of optical constants, and Mie scattering calculations for small particles, is deferred to a future publication. This laboratory work is the extension of earlier studies, which concentrated mainly on the $4000-2500 \mathrm{~cm}^{-1}$ $(2.5-4.0 \mu \mathrm{m})$ region (Hagen, Tielens, and Greenberg 1981, $1983 a$ ). Figure 3 shows the spectra of $\mathrm{H}_{2} \mathrm{O}$ and binary mixtures of $\mathrm{H}_{2} \mathrm{O}$ and other molecules. Figure 4 shows the spectra of simple hydrocarbons. Table 2 summarizes the peak frequencies of the different absorption bands of these molecules in the $2000-1250 \mathrm{~cm}^{-1}(5-8 \mu \mathrm{m})$ region. 


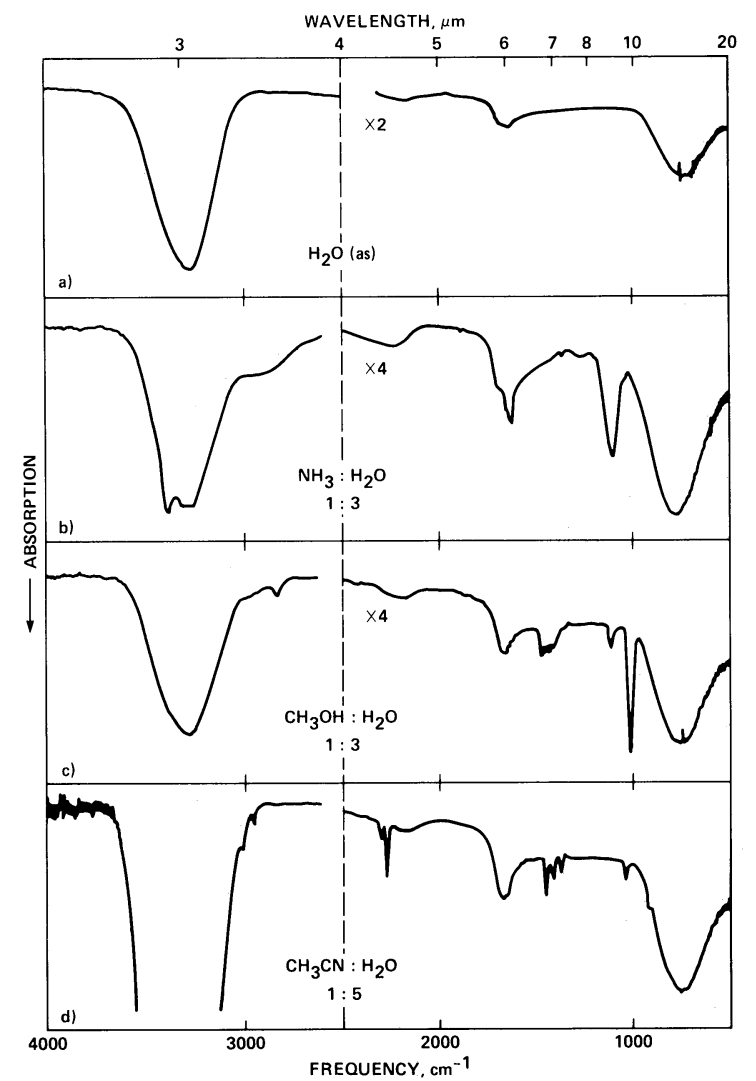

FIG. 3.-Infrared laboratory spectra of $\mathrm{H}_{2} \mathrm{O}$ and mixtures of $\mathrm{H}_{2} \mathrm{O}$ and other molecules at $10 \mathrm{~K}$ taken at $2 \mathrm{~cm}^{-1}$ resolution. Note that except for $(d)$ the spectra are expanded below $2500 \mathrm{~cm}^{-1}$.

\section{i) The $\mathrm{OH}$ Bending Mode in the $6.0 \mu \mathrm{m}$ Region}

The $\mathrm{OH}$ bending mode in pure, unannealed, $\mathrm{H}_{2} \mathrm{O}($ as) at 10 $\mathrm{K}$ occurs at $1665 \mathrm{~cm}^{-1}(6.0 \mu \mathrm{m})$. It consists of a relatively narrow peak and a low-frequency wing extending to about $1000 \mathrm{~cm}^{-1}(10 \mu \mathrm{m})$. The peak strength of this band, relative to the $\mathrm{OH}$ stretching band (at $3.08 \mu \mathrm{m}$ ) is about $7 \%$ (Hagen, Tielens, and Greenberg 1981). Upon heating to $\sim 100 \mathrm{~K}$ the band becomes considerably broader, the narrow component is reduced, and the peak shifts to somewhat lower frequencies $\left(\sim 20 \mathrm{~cm}^{-1}, 0.1 \mu \mathrm{m}\right)$. This is probably due to coupling of the bending mode with the overtone of the librational band (Fermi resonance; Hagen, Tielens, and Greenberg 1981). Because of the decrease in the disorder in the $\mathrm{H}_{2} \mathrm{O}$ network upon heating (annealing), the librational band shifts to higher frequencies $\left[763 \mathrm{~cm}^{-1}(13.1 \mu \mathrm{m})\right.$ at $10 \mathrm{~K}$ versus $800 \mathrm{~cm}^{-1}(12.5 \mu \mathrm{m})$ at 130 $\mathrm{K}$ (Hagen and Tielens 1982)]. Because of the decrease in the energy separation, coupling between the bending mode (at $1665 \mathrm{~cm}^{-1}$ ) and the overtone of the librational mode may become more important at higher temperatures.

Increasing dilution of $\mathrm{H}_{2} \mathrm{O}$ in a non-hydrogen bonding environment shifts the bending mode to lower frequencies. Polymeric $\mathrm{H}_{2} \mathrm{O}$ (e.g., $5 \% \leq X\left(\mathrm{H}_{2} \mathrm{O}\right) \leq 50 \%$, where $X$ indicates the concentration) absorbs around $1640 \mathrm{~cm}^{-1}(6.10 \mu \mathrm{m})$ and monomeric (fully isolated) $\mathrm{H}_{2} \mathrm{O}$ (e.g., $X\left(\mathrm{H}_{2} \mathrm{O}\right) \leq 1 \%$ ) absorbs around $1600 \mathrm{~cm}^{-1}(6.25 \mu \mathrm{m}$, van Thiel, Becker, and Pimentel 1957; Hagen and Tielens 1981). This change in peak frequency is accompanied by a strong decrease in line width and a strong increase in peak strength. The integrated intensity, however, remains about the same $\left(\sim 8.3 \times 10^{-18} \mathrm{~cm}^{-1}\right.$

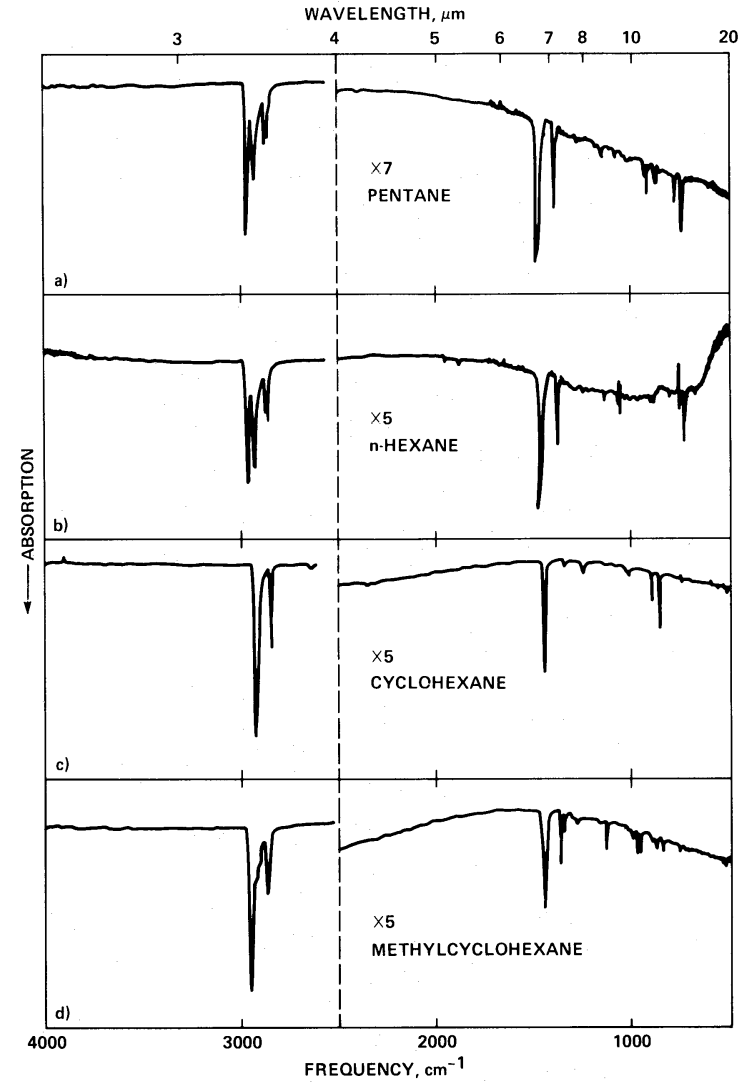

FIG. 4.- Infrared laboratory spectra of saturated hydrocarbons at $10 \mathrm{~K}$ taken at $2 \mathrm{~cm}^{-1}$ resolution. Note that the spectra are expanded below 2500 $\mathrm{cm}^{-1}$.

molecule ${ }^{-1}$ ). It should be emphasized that similar changes occur in the shape and peak frequency of the $\mathrm{OH}$ stretching mode upon dilution. The integrated intensity of the $\mathrm{OH}$ stretching mode decreases considerably upon dilution, however. Upon heating, the $\mathrm{H}_{2} \mathrm{O}$ may start to diffuse through the matrix, forming polymers and finally $\mathrm{H}_{2} \mathrm{O}$ (as). The spectra of such heated mixtures will be similar to those of less diluted samples at $10 \mathrm{~K}$.

Dilution of $\mathrm{H}_{2} \mathrm{O}$ in a strong hydrogen bonding environment can increase the peak frequency, up to perhaps $1700 \mathrm{~cm}^{-1}$ $(5.88 \mu \mathrm{m}) . \mathrm{NH}_{3}$ forms an exception to this rule. For $\mathrm{NH}_{3}$ concentrations larger than about $10 \%$, the peak occurs around $1630 \mathrm{~cm}^{-1}(6.13 \mu \mathrm{m})$. This is the peak frequency of the deformation mode of $\mathrm{NH}_{3}$. Apparently this mode gains in strength upon complexing with $\mathrm{H}_{2} \mathrm{O}$, relative to the $\mathrm{NH}$ stretching and umbrella modes. We think that this is an intermolecular analog of the Fermi resonance between the $\mathrm{H}_{2} \mathrm{O}$ bending mode and the overtone of the librational mode discussed above.

ii) The $\mathrm{CH}$ Deformation Modes in the $7 \mu \mathrm{m}$ Region

These modes are extensively reviewed in Bellamy (1960). The methyl and methylene deformation modes occur close to the same frequency for almost all saturated hydrocarbons $\left(\mathrm{CH}_{3}\right.$ : $1450 \mathrm{~cm}^{-1}[6.90 \mu \mathrm{m}]$ and $1375 \mathrm{~cm}^{-1}$ [7.27 $\left.\mu \mathrm{m}\right] ; \mathrm{CH}_{2}: 1465$ $\mathrm{cm}^{-1}[6.83 \mu \mathrm{m}]$; see Table 2). The relative strengths of these bands is a good indicator of the ratio of $\mathrm{CH}_{2}$ to $\mathrm{CH}_{3}$ groups (Bellamy 1960). Exceptions to this frequency rule can occur when the $\mathrm{CH}_{2}$ or $\mathrm{CH}_{3}$ group is attached to a strongly electronegative group. For example, in $\mathrm{CH}_{3} \mathrm{OH}$ they occur at 1477 $\mathrm{cm}^{-1}(6.77 \mu \mathrm{m})$ and $1460 \mathrm{~cm}^{-1}(6.85 \mu \mathrm{m})$. Similarly, the $\mathrm{CH}_{3}$ 
TABLE 2

ABSORPTIONS IN THE 5-8 $\mu$ m ReGION OF THE SPECTRA SHOWN IN FIGURES 3 AND 4

\begin{tabular}{|c|c|}
\hline Compound & $\begin{array}{l}\text { Peak Frequency } \\
\left(\mathrm{cm}^{-1}\right)\end{array}$ \\
\hline pentane .... & $\begin{array}{l}1470 \\
1378\end{array}$ \\
\hline n-hexane $\ldots \ldots \ldots \ldots \ldots \ldots$ & $\begin{array}{l}1472 \mathrm{~s} \\
1382 \mathrm{~m}\end{array}$ \\
\hline cyclohexane & 1450 \\
\hline methylcyclohexane ......... & $\begin{array}{l}1450 \mathrm{~s} \\
1375 \mathrm{~m}\end{array}$ \\
\hline $\mathrm{H}_{2} \mathrm{O} \ldots \ldots \ldots \ldots \ldots \ldots \ldots \ldots \ldots$ & 1665 \\
\hline $\begin{array}{l}\mathrm{H}_{2} \mathrm{O} / \mathrm{NH}_{3} \\
\quad(3 / 1) \ldots \ldots \ldots \ldots \ldots \ldots . . . \ldots \ldots\end{array}$ & $\begin{array}{l}1630 \\
1690(\mathrm{sh})\end{array}$ \\
\hline $\begin{array}{l}\mathrm{H}_{2} \mathrm{O} / \mathrm{CH}_{3} \mathrm{OH} \\
\quad(3 / 1) \ldots \ldots \ldots .\end{array}$ & $\begin{array}{l}1660 \\
1475 \\
1457 \\
1445(p) \\
1420\end{array}$ \\
\hline $\begin{array}{c}\mathrm{H}_{2} \mathrm{O} / \mathrm{CH}_{3} \mathrm{CN} \\
(5 / 1) \ldots \ldots \ldots \\
\ldots\end{array}$ & $\begin{array}{l}1660 \\
1443 \\
1410(p) \\
1368\end{array}$ \\
\hline
\end{tabular}

NOTE.-The peak frequencies are measured at $2 \mathrm{~cm}^{-1}$ resolution. The spectra in Figs. 3 and 4 are shown at $32 \mathrm{~cm}^{-1}$ resolution. Strong and moderate band strengths are indicated by $s$ and $m$, respectively. A shoulder on a band is indicated by (sh). The band center is marked by (p).

deformation modes in $\left(\mathrm{CH}_{3}\right)_{2} \mathrm{CO}$ occur at $1420 \mathrm{~cm}^{-1}$ and 1367 $\mathrm{cm}^{-1}(7.04$ and $7.32 \mu \mathrm{m})$. The peak frequency of the $\mathrm{CH}$ deformation modes in $\mathrm{CH}_{4}$, a molecule which is a class by itself, is also shifted from the positions for all other saturated hydrocarbons (e.g., $1299 \mathrm{~cm}^{-1}, 7.7 \mu \mathrm{m}$ ). In unsaturated hydrocarbons the bending modes are also shifted to lower frequencies. For example, in $\mathrm{C}_{6} \mathrm{H}_{6}$ they occur in the region $1200-650 \mathrm{~cm}^{-1}$ $(8.5-15.4 \mu \mathrm{m})$, while in $\mathrm{C}_{2} \mathrm{H}_{2}$ they are at about 1400 and 750 $\mathrm{cm}^{-1}$ (7.1 and $\left.13.3 \mu \mathrm{m}\right)$.

Generally the peak frequency is not shifted by more than 10 $\mathrm{cm}^{-1}$, nor is the strength of these modes influenced by the presence of $\mathrm{H}_{2} \mathrm{O}$ in the mixture. Likewise the temperature is expected to have only a small effect on the peak frequency $\left( \pm 20 \mathrm{~cm}^{-1}, 0.1 \mu \mathrm{m}\right)$ and strength. Actually the strength of the $\mathrm{CH}$ deformation modes in simple saturated hydrocarbons remains quite constant at $3-5 \times 10^{-18} \mathrm{~cm}^{-1}$ per $\mathrm{CH}_{3}$ group (d'Hendecourt 1984). However, the strength of the $\mathrm{CH}$ deformation modes among different classes of molecules, for example aliphatic hydrocarbons, ketones, and ethers, can vary by as much as a factor of 5 (Gribov and Smirnov 1961).

iii) Other Vibrational Modes in the 5-8 $\mu \mathrm{m}$ Region

Other characteristic groups which may absorb in this wavelength region are the $\mathrm{C}=\mathrm{C}, \mathrm{C}=\mathrm{N}, \mathrm{C}=\mathrm{O}$ stretching modes. In particular ketones, aldehydes, and carboxylic acids show a strong $\mathrm{C}=\mathrm{O}$ stretching absorption band in the region 1870 $1540 \mathrm{~cm}^{-1}(5.35-6.50 \mu \mathrm{m})$. Of these the $\mathrm{C}=\mathrm{O}$ stretch in $\mathrm{H}_{2} \mathrm{CO}$ which occurs at $1740 \mathrm{~cm}^{-1}(5.74 \mu \mathrm{m})$ in monomeric $\mathrm{H}_{2} \mathrm{CO}$ (Khoskhoo and Nixon 1973) is particularly significant. Generally shifts of up to $50 \mathrm{~cm}^{-1}(0.25 \mu \mathrm{m})$ can be expected due to environmental effects (Nelander 1980). For example, in mix- tures with $\mathrm{H}_{2} \mathrm{O}$, the $\mathrm{C}=\mathrm{O}$ stretching mode in $\mathrm{H}_{2} \mathrm{CO}$ shifts to lower frequencies $\left(1720 \mathrm{~cm}^{-1}, 5.81 \mu \mathrm{m}\right.$; Kitta and Kratschmer 1983 and van der Zwet 1984).

\section{DISCUSSION}

\section{a) The Observed Absorption Features}

All of the 5-8 $\mu \mathrm{m}$ spectra displayed in Figure 2 show some evidence for absorption features. The spectrum of Mon R2-IRS2 shows clear evidence for the 6.0 and $6.8 \mu \mathrm{m}$ features previously discovered in other sources (W33A; Soifer et al. 1979). The shapes of these absorption features in Mon R2-IRS2 are, however, quite different from those in W33A. In Figure 5 the absorption features in the two sources are compared. This figure has been prepared as follows. The optical depth of the absorption features in Mon R2-IRS2 is measured as a function of wavelength by assuming a linear continuum between 5.2 and $7.8 \mu \mathrm{m}$. While not perfect, this is probably a good approximation to the real continuum (cf. Fig. 2). The absorption features in Mon R2-IRS2 are then expanded by assuming an optical depth of 2.0 at $6.0 \mu \mathrm{m}$ to match that observed in W33A and scaling the other wavelengths accordingly. The resulting features are plotted on the W33A spectrum, assuming a linear continuum between 5.5 and $7.9 \mu \mathrm{m}$ for W33A. Note that this procedure exagerates the statistical errorbars on the Mon R2-IRS2 data, because the absorption in this source is much shallower than in W33A.

This comparison shows that the shapes of the absorption features are very different in the two sources. In Mon R2-IRS2 the $6.0 \mu \mathrm{m}$ feature starts at $5.2 \mu \mathrm{m}$, rather than $5.5 \mu \mathrm{m}$ as in W33A. In effect, because our spectrum starts only at $5.2 \mu \mathrm{m}$, this feature may start at even shorter wavelengths. The $6.0 \mu \mathrm{m}$ feature in Mon R2-IRS2 also shows an abrupt rise at $6.1 \mu \mathrm{m}$ $\left(1630 \mathrm{~cm}^{-1}\right)$ which is not present in the W33A spectrum. The increased strength of the $6.8 \mu \mathrm{m}$ feature in Mon R2-IRS2, relative to the $6.0 \mu \mathrm{m}$ feature, exagerates the differences in this feature between the two sources. However, even when the two

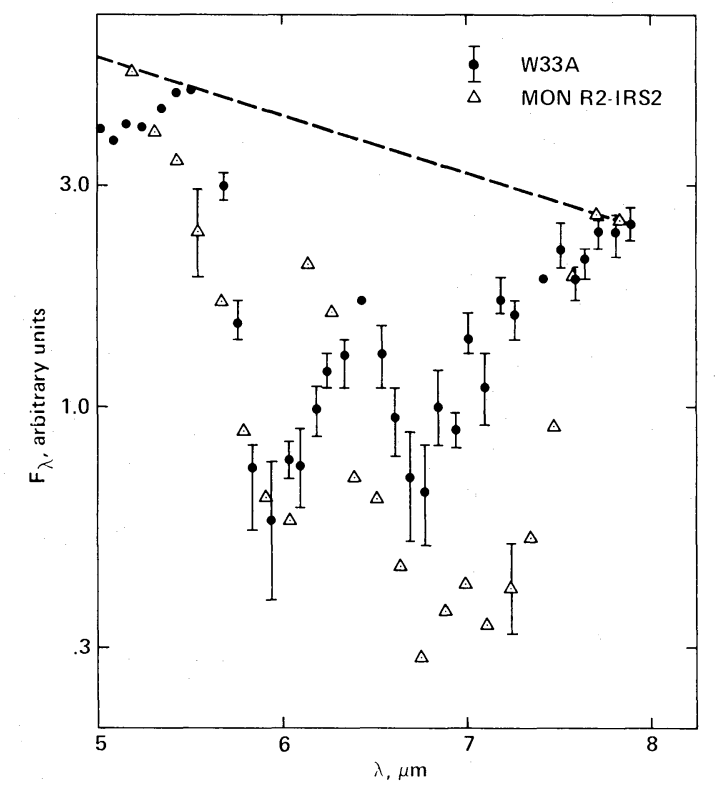

FIG. 5.-Comparison of the 5-8 $\mu \mathrm{m}$ spectrum of Mon R2-IRS2 with that previously published for W33A (Soifer et al. 1979). The spectra are normalized to each other at $6.0 \mu \mathrm{m}$. See text ( $\mathrm{IV} a$ ) for a detailed discussion. 
spectra are normalized at $6.8 \mu \mathrm{m}$, they differ markedly. The Mon R2-IRS2 $6.8 \mu \mathrm{m}$ feature is much broader. The substructure at $7.1 \mu \mathrm{m}$ suggest that this difference is due to the presence of an additional absorption feature, besides the narrower W33A-type $6.8 \mu \mathrm{m}$ band. However, within the errors the data might also be interpreted as showing one very broad absorption band peaking at about $7.0 \mu \mathrm{m}$. Slightly higher resolution $(\lambda / \delta \lambda \approx 150)$ is needed to settle this question.

Although the detailed differences between the two sources do depend somewhat on the continuum assumed for W33A, the conclusion that the shape of the 6.0 and $6.8 \mu \mathrm{m}$ band differs in the two sources remains valid. For example, assuming a 450 $\mathrm{K}$ blackbody fitted at $5.5 \mu \mathrm{m}$ for the continuum of $\mathrm{W} 33 \mathrm{~A}$, which gives a reasonable fit to the 2-2.5 and 4-5 $\mu \mathrm{m}$ data (Soifer et al. 1979), actually increases the differences between the two sources, in particular around $7.5 \mu \mathrm{m}$. Because of the uncertain continuum level, possible variations in the ratio of 6.8 to $6.0 \mu \mathrm{m}$ strength, and the possible presence of nonstatistical errors in the CVF spectrum of W33A, it is difficult to make a meaningful, quantitative, statistical analysis of the differences between the two spectra. A reliable, qualitative discussion of the differences is possible and warranted, however. Seven points in the $6.0 \mu \mathrm{m}$ band differ by $1-3 \sigma$ (Fig. 5). Actually, only two points overlap well within $1 \sigma$, of which one is forced by the normalization procedure to agree. Similarly, six points in the $6.8 \mu \mathrm{m}$ feature differ, while only three coincide, when the features are normalized at $6.8 \mu \mathrm{m}$. Three of the nonoverlapping points in this band differ by at least $3 \sigma$. The differences in the shape and relative intensities of the 6.0 and $6.8 \mu \mathrm{m}$ band between these two sources are therefore statistically significant and the difference is real.

The spectra of BN and NGC 2264 show an almost continuous absorption from about 5.2 to $7.8 \mu \mathrm{m}$. At first sight the 6.0 and $6.8 \mu \mathrm{m}$ features in these two sources seem to be much broader than those in Mon R2-IRS2. However, to some extent this impression is due to the shallowness of the features in these two sources. In effect, a detailed comparison of these spectra with that of Mon R2-IRS2, similar to that of W33A described above, shows that the 6.0 and $6.8 \mu \mathrm{m}$ absorption features in these sources are rather similar, except for additional absorption around 5.5 and $6.3 \mu \mathrm{m}$ in the BN and NGC 2264 spectra (cf Fig. 2). However, while statistical errors for the observed fluxes are low, because of the shallowness of the absorption features in BN and NGC 2264, the error bars in the optical depth are relatively large. The differences with the Mon R2-IRS2 spectrum may therefore not be significant. Higher resolution spectra are therefore needed to confirm their presence. Note that all spectra show distinct structure at $6.8 \mu \mathrm{m}$ (Fig. 2). Although the significance in any one spectrum alone is low, the repeated appearance suggests that it is real.

For P13S the evidence for absorption features in the 5-8 $\mu \mathrm{m}$ spectrum is not conclusive, because of the large statistical error bars and the shallowness of the absorption. By smoothing all the data, a comparison of the spectrum of this source with that of BN suggests, however, that the broad and shallow features of $\mathrm{BN}$ are also present in $\mathrm{P} 13 \mathrm{~S}$.

It is difficult to categorize the absorption features in previously published 5-8 $\mu \mathrm{m}$ (CVF) spectra. Probably NGC 7538IRS9 and AFGL 2136 have 6.0 and $6.8 \mu \mathrm{m}$ features similar to W33A, while AFGL 2884 (S140) is similar to Mon R2-IRS2 (Wilner et al. 1982). However, until confirmed by further observations, this classification should be viewed with some caution, because of the systematic errors inherently possible with a
CVF spectrometer. None of the other 10 or so sources with published 5-8 $\mu$ m CVF (Willner et al. 1982) can be easily classified. Although all show some evidence for absorption features in this wavelength region, the possible presence of spurious features hampers such an analysis considerably.

At this stage it is interesting to note that the $5-8 \mu \mathrm{m}$ spectrum of Sgr A-W(N) (Willner et al. 1979) shows some evidence for the presence of a broad absorption feature (Hagen, Allamandola, and Greenberg 1980), which appears quite similar to that of BN. Of course, this resemblance might be superficial, caused by the shallowness of the absorption features in both sources. It might, however, also imply that this broad absorption band is a general characteristic of the dust, even in the diffuse interstellar medium. If this is the case, the broad component may not be solely associated with the growth of icy grain mantles in molecular clouds. In $\S \mathrm{IV} c$ further arguments for this suggestion are presented. Here we merely want to note that this picture derives qualitative support from the observation that the $3.08 \mu \mathrm{m}$ ice band in $\mathrm{W} 33 \mathrm{~A}$ is the strongest ice band observed to date. The low column density of accreted ices toward the other sources probably produces only weak 6.0 and $6.8 \mu \mathrm{m}$ features, which are lost, or appear as small structures in the broad, shallow features for these sources. The repeated appearance of structure at $6.8 \mu \mathrm{m}$ in all sources suggests that this is the case. Clearly, higher resolution spectra are needed to confirm this.

\section{b) Identifications}

The interpretation of the 5-8 $\mu \mathrm{m}$ spectrum of W33A is expected to be more straightforward than for the other sources. The narrowness of the absorption features in the spectrum of this source suggests that only a few, simple molecules are dominant. The increased width and the possible substructure in the other spectra suggest mixtures that are more complex and consequently more difficult to interpret. We will start, therefore, by comparing the spectrum of W33A with the laboratory spectra, discussed in $\S$ III.

$$
\text { i) 5-8 } \mu \mathrm{m} \text { Spectra of } W 33 \mathrm{~A}
$$

Comparison of the observations with the laboratory data is somewhat hampered by the unknown continuum level. For W33A we have assumed that the continuum is given by a straight line, connecting $5.5 \mu \mathrm{m}$ with $7.9 \mu \mathrm{m}$. Comparing the observed $6.0 \mu \mathrm{m}$ band with the $\mathrm{OH}$ bending mode in $\mathrm{H}_{2} \mathrm{O}$ (as) at $10 \mathrm{~K}$ shows reasonable agreement (Fig. $6 a$ ). The agreement particularly around $6.5 \mu \mathrm{m}$, is slightly better if a blackbody fitted to the data from 2.5 to $4.0 \mu \mathrm{m}$ is chosen to construct the continuum (Tielens 1984). The presence of this band supports the identification of the $3.08 \mu \mathrm{m}$ band with the $\mathrm{OH}$ stretching mode in $\mathrm{H}_{2} \mathrm{O}$. It should be noted, however, that more complex mixtures cannot be excluded. First, as long as the concentration of $\mathrm{H}_{2} \mathrm{O}$ in the grain mantle is at least $50 \%$, the spectrum will still peak at $6.0 \mu \mathrm{m}$. Second, the low signal-to-noise ratio and low resolution may hide some substructure. For example, comparing the observed $6.0 \mu \mathrm{m}$ band with laboratory spectra of $\mathrm{NH}_{3} / \mathrm{H}_{2} \mathrm{O}$ mixtures suggests that the concentration of $\mathrm{NH}_{3}$, if present in the grain mantle, is less than $10 \%$. Otherwise the band would peak at $6.13 \mu \mathrm{m}$. However, if, for instance, $\mathrm{H}_{2} \mathrm{CO}$ or other carbonyl containing molecules, which absorb near 5.8 $\mu \mathrm{m}$, are abundant in the grain mantle, as suggested by theoretical calculations (Tielens and Hagen 1982) and by laboratory experiments on photolysis of grain mantles (Allamandola 1984), then at low resolution blending with the strong absorp- 


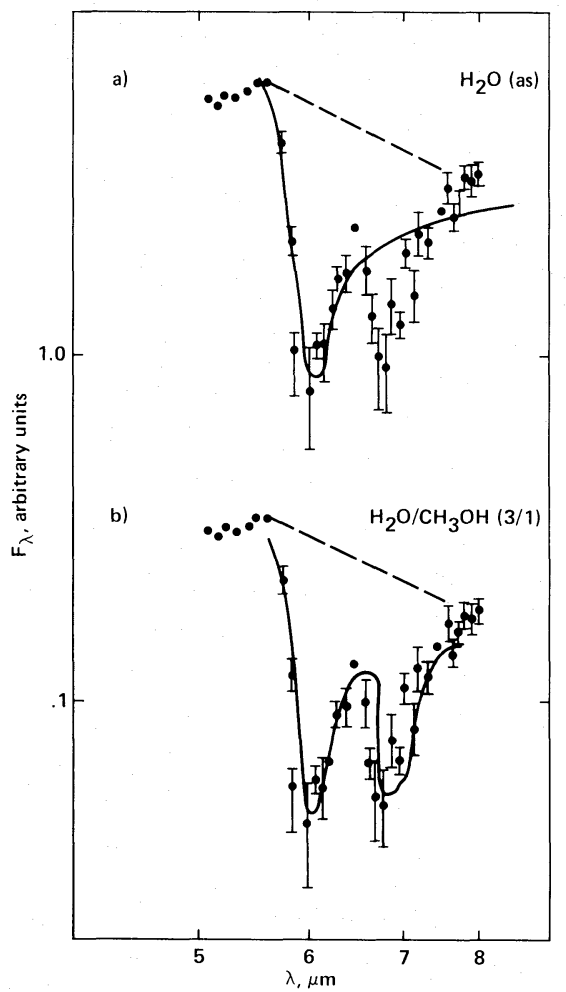

FIG. 6.-The observed 5-8 $\mu \mathrm{m}$ spectrum of W33A is compared to $(a)$ the laboratory spectrum of pure amorphous $\mathrm{H}_{2} \mathrm{O}$ at $10 \mathrm{~K}$ and $(b)$ the spectrum of a mixture of $\mathrm{H}_{2} \mathrm{O}$ and $\mathrm{CH}_{3} \mathrm{OH}$. Both laboratory spectra are at $32 \mathrm{~cm}^{-1}$ resolution.

tion due to the $\mathrm{C}=\mathrm{O}$ stretch may shift the apparent peak center back to $6.0 \mu \mathrm{m}$.

Notwithstanding, the observed $6.0 \mu \mathrm{m}$ line is probably still mainly due to the $\mathrm{OH}$ bending mode in $\mathrm{H}_{2} \mathrm{O}$. Accepting this identification and assuming a peak strength of $4.2 \times 10^{-20}$ $\mathrm{cm}^{2}$ per molecule (Hagen, Tielens, and Greenberg 1981), the observed optical depth of 2.0 implies a column density of $\mathrm{H}_{2} \mathrm{O}$ in the grain mantles of $4.7 \times 10^{19} \mathrm{~cm}^{-2}$. The optical depth in the silicate band, corrected for underlying silicate emission, is 7.8 (Willner et al. 1982). This translates to a total hydrogen column density of $2.2 \times 10^{23} \mathrm{~cm}^{-2}$, where we have assumed $\left(A_{v} / \tau\right)=15$ (Gillett et al. 1975) and $N_{\mathrm{H}} / A_{v}=1.9 \times 10^{21} \mathrm{~cm}^{-2}$ (Bohlin, Savage, and Drake 1978). Thus, assuming cosmic abundance, about $34 \%$ of all the oxygen is in the form of solid $\mathrm{H}_{2} \mathrm{O}$. If the continuum is given by a $450 \mathrm{~K}$ blackbody fitted to the $2-5 \mu \mathrm{m}$ data, then this estimate is raised to about $37 \%$.

Finally, as noted in $\S$ III $b$ (i) the shape of the $\mathrm{OH}$ bending mode is temperature dependent, presumably due to coupling with the overtone of the librational band. However, since this becomes really important only for temperatures above $100 \mathrm{~K}$, it is not important in the interstellar medium, where the evaporation temperature of $\mathrm{H}_{2} \mathrm{O}$ is about $95 \mathrm{~K}$ (Nakagawa 1980). This probably explains why the $6.0 \mu \mathrm{m}$ band in the spectrum of $\mathrm{OH} 0739$, which arises from a circumstellar shell and is associated with pure $\mathrm{H}_{2} \mathrm{O}$ grain mantles at $\approx 70 \mathrm{~K}$ (Hagen, Tielens, and Greenberg 1983b), is so similar to the $6.0 \mu \mathrm{m}$ ice band in the molecular mixtures in W33A (Soifer et al. 1981). The absence of coupling between the $\mathrm{OH}$ bending mode and the overtone of the librational band in the spectrum of W33A implies that the librational band occurs longwards of $13 \mu \mathrm{m}$ (Tielens 1984). This and its large width may have prevented its detection in this source (Hagen and Tielens 1982). As an aside, we note that it has been suggested that the librational band of $\mathrm{H}_{2} \mathrm{O}$ has been detected at about $11.5 \mu \mathrm{m}$ in $\mathrm{OH} 0739$. This is, in fact, incompatable with the observed shape of the $6.0 \mu \mathrm{m}$ band in this source. It should be emphasized, however, that $\mathrm{OH} 0739$ is a complex, infrared, reflection nebula, and one should be careful in analyzing its spectrum (Tielens, Werner, and Capps 1984).

The $6.8 \mu \mathrm{m}$ band in W33A occurs at the correct frequency for identification with the deformation modes in saturated hydrocarbons (Hagen, Allamandola, and Greenberg 1980; Puetter et al. 1979). Additional support for this identification comes from the presence of a small $3.4 \mu \mathrm{m}$ absorption feature superposed on the wing of the broad $3 \mu \mathrm{m}$ ice band. This is the position of the $\mathrm{CH}$ stretch in saturated hydrocarbons. In Figure $6 b$ the observed $\mathrm{W} 33 \mathrm{~A}$ spectrum is compared to the laboratory spectrum of a mixture of $\mathrm{H}_{2} \mathrm{O}$ and $\mathrm{CH}_{3} \mathrm{OH}(3 / 1)$ at comparable resolution. The two agree reasonably well, in view of the observed spectrum. It should be emphasized that this is not a unique fit to the observed spectrum. As discussed in $\S$ III the modes giving rise to the $6.8 \mu \mathrm{m}$ band are only slightly sensitive to the environment of the $\mathrm{CH}_{2}$ or $\mathrm{CH}_{3}$ groups in saturated hydrocarbons. $\mathrm{CH}_{3} \mathrm{CN}$, for example, may provide an equally good fit at this resolution. Higher resolution $\left(\lambda / \Delta \lambda \approx 10^{3}\right)$ spectra could distinguish between these molecules (c.f., Figs. 3 and 4). The position and shape of the $6.8 \mu \mathrm{m}$ band shows that unsaturated hydrocarbons are not dominant and in particular aromatics, alkynes, alkenes, and simple aliphatic ketones can be ruled out since the $\mathrm{CH}$ bending modes in these molecules are shifted longward of $6.8 \mu \mathrm{m}$. Although other modes of these molecules may fall in this wavelength region, for example the $\mathrm{C}=\mathrm{C}$ stretch in $\mathrm{C}_{6} \mathrm{H}_{6}$, these are generally too weak and imply other bands not found in the observed spectrum. Because of the low signal-to-noise ratio, it is difficult to estimate reliable upper limits for the amounts of these molecules.

If we accept the identification of the $6.8 \mu \mathrm{m}$ band in W33A with saturated hydrocarbons then the amount of material involved can be estimated. Estimating the continuum from the low frequency wing of the $\mathrm{H}_{2} \mathrm{O}$ bending mode (Fig. $6 a$ ), yields an equivalent width of about $100 \mathrm{~cm}^{-1}$ for the $6.8 \mu \mathrm{m}$ band. This implies a column density of $\mathrm{C}$ in saturated hydrocarbons of about $2.5 \times 10^{19} \mathrm{~cm}^{-2}$, or about $30 \%$ of all the carbon along the line of sight. This value is uncertain by perhaps a factor of 2 due to the uncertain continuum level and the large error bars associated with this feature. If all saturated hydrocarbons contain one $\mathrm{CH}_{3}$ group, then the ratio of these molecules to $\mathrm{H}_{2} \mathrm{O}$ is about 0.5 .

ii) 5-8 $\mu \mathrm{m}$ Spectra of Mon R2-IRS2, BN, and NGC 2264

As discussed in $\S \mathrm{IV} a$, the large width and substructure of the observed bands in Mon R2-IRS2, BN, and NGC 2264 suggest that the grain mantles along the line of sight towards these objects contain a more complex mixture than those in W33A. In Figure 7, the observed spectrum of Mon R2-IRS2 is compared to the laboratory spectrum of $\mathrm{H}_{2} \mathrm{O}$ and of $\mathrm{H}_{2} \mathrm{O} / \mathrm{CH}_{3} \mathrm{OH}$ $(3 / 1)$. Obviously these species can only account for a fraction of the observed features. This is not too surprising, since these laboratory spectra fit the W33A spectra so well. In effect, this merely restates that the absorption features in W33A and Mon R2-IRS2 are different (cf. $§$ IVa).

This comparison shows that the $\mathrm{OH}$ bending mode does not dominate the observed spectrum at $6.0 \mu \mathrm{m}$. It should be noted 


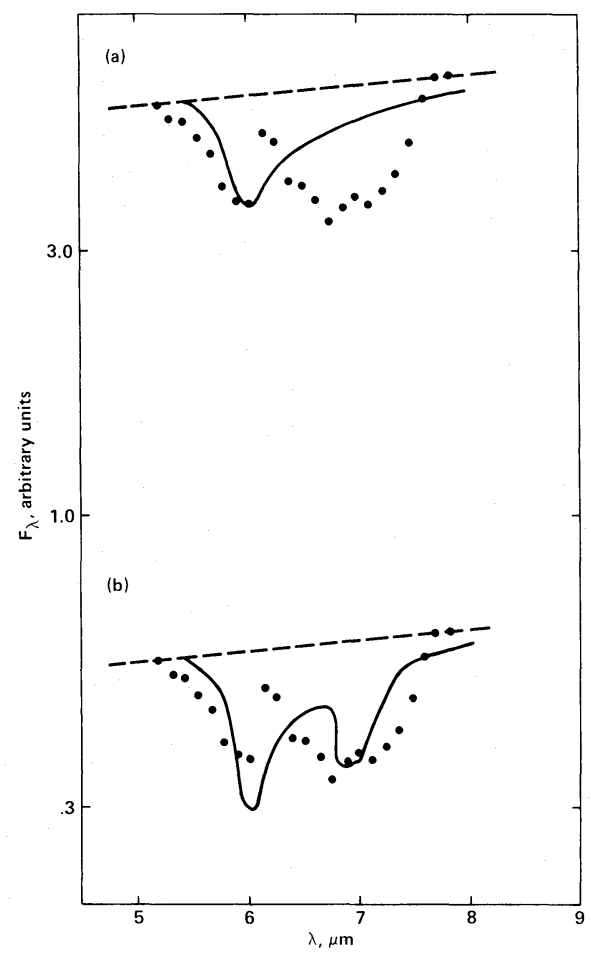

Fig. 7.- The observed 5-8 $\mu \mathrm{m}$ spectrum of Mon R2-IRS2 is compared to (a) the laboratory spectrum of pure amorphous $\mathrm{H}_{2} \mathrm{O}$ at $10 \mathrm{~K}$ and $(b)$ the spectrum of a mixture of $\mathrm{H}_{2} \mathrm{O}$ and $\mathrm{CH}_{3} \mathrm{OH}$. Both spectra are at $32 \mathrm{~cm}^{-1}$ resolution. Note that some of the structure in the $\mathrm{CH}$ deformation mode of $\mathrm{CH}_{3} \mathrm{OH}$ at $2 \mathrm{~cm}^{-1}$ resolution is lost.

that this conclusion is not in direct conflict with the interpretation of the $3.08 \mu \mathrm{m}$ band as the $\mathrm{OH}$ stretching mode in $\mathrm{H}_{2} \mathrm{O}$. The observed optical depth at $3.08 \mu \mathrm{m}$ of about 2.0 , if due to pure $\mathrm{H}_{2} \mathrm{O}$ (as), implies an optical depth in the $\mathrm{OH}$ bending mode at $6.0 \mu \mathrm{m}$ of about 0.15 . In mixtures of $\mathrm{H}_{2} \mathrm{O}$ and other molecules, the $\mathrm{OH}$ bending mode is somewhat stronger relative to the $\mathrm{OH}$ stretching mode, but probably not more than by a factor of 2 . Otherwise the $3.08 \mu \mathrm{m}$ band would have a very different shape; less symmetric and with structure indicative of dimers, trimers, and higher polymers. The optical depth at 6.0 $\mu \mathrm{m}$, observed in Mon R2-IRS2 is, however, about 0.5 , and the $\mathrm{H}_{2} \mathrm{O}$ bending mode may very well be blended with other absorptions. Clearly other molecules contribute substantially to the $6.0 \mu \mathrm{m}$ absorption band (Fig. 7). An obvious candidate for such absorption is the $\mathrm{C}=\mathrm{O}$ stretching vibration.

The possible substructure in the $6.8 \mu \mathrm{m}$ band observed in Mon R2-IRS2 at 6.8 and $7.1 \mu \mathrm{m}$ is suggestive of absorption by a family of saturated hydrocarbons. Simple saturated hydrocarbons show a strong absorption band around $6.8 \mu \mathrm{m}$ and a weaker one around $7.1 \mu \mathrm{m}$ (cf. the spectrum of pentane in Fig. 4 and Table 2). The presence of strongly electronegative groups in the molecules shifts these peaks (see Fig. 3 and Table 2). Thus a mixture of saturated hydrocarbons with and without such strongly electronegative groups will give rise to a broader feature and can shift the peak or produce substructure at longer wavelengths. Note, however, that the mixture has to be more complex than those shown in Figure 3, since the absorption at $7.1 \mu \mathrm{m}$ in these laboratory spectra is not strong enough. Acetone, for example, would provide a much better fit (Hagen, Tielens, and Greenberg 1983a). The presence of the $7.1 \mu \mathrm{m}$ band, or equivalently a broadening and shift towards longer wavelengths, could also be produced by a mixture of saturated and unsaturated (for example $\mathrm{C}_{2} \mathrm{H}_{2}$ ) hydrocarbons.

It is difficult to identify the molecules responsible for the absorption in the spectra of BN and NGC 2264, because of the breadth and shallowness of the absorption. As for Mon R2IRS2, the increased width of the 6.0 and $6.8 \mu \mathrm{m}$ feature, with respect to $\mathrm{W} 33 \mathrm{~A}$, suggests the presence of a mixture of saturated hydrocarbons with and without strongly electronegative groups, or a mixture of saturated and unsaturated hydrocarbons.

\section{c) Implications for Interstellar Grain Chemistry}

The detection of these broad absorption features has important ramifications for our understanding of interstellar grain chemistry. Calculations of interstellar gas phase chemistry show that in molecular clouds most of the gas phase carbon is tied up in CO (Langer 1976; Prasad and Huntress 1980). Upon accretion on a grain surface, hydrogen addition reactions will convert $\mathrm{CO}$ to $\mathrm{HCO}$ and perhaps eventually $\mathrm{H}_{2} \mathrm{CO}$ (Tielens and Hagen 1982; d'Hendecourt 1984). It has been speculated that hydrogen addition to $\mathrm{H}_{2} \mathrm{CO}$ may form $\mathrm{CH}_{3} \mathrm{OH}$ (Tielens and Hagen 1982). Although these reactions may have activation energies, an $\mathrm{H}$ atom on a grain surface is expected to be able to tunnel through a $4000 \mathrm{~K}$ activation barrier and react (Tielens and Hagen 1982). The initiating reaction, $\mathrm{H}+\mathrm{CO} \rightarrow \mathrm{HCO}$, has in fact been observed to occur at $15 \mathrm{~K}$ in matrices (van IJzendoorn et al. 1983). Some controversy exists about the reaction $\mathrm{H}+\mathrm{HCO} \rightarrow \mathrm{H}_{2} \mathrm{CO}$ (d'Hendecourt 1984) and the reaction producing $\mathrm{CH}_{3} \mathrm{OH}$ has not yet been studied in the laboratory. Model calculations, including gas phase and grain surface chemistry, predict that grain mantles, which are rich in $\mathrm{H}_{2} \mathrm{O}(\sim 50 \%)$ also contain a large abundance of $\mathrm{H}_{2} \mathrm{CO}$ ( $\sim 30 \%$; Tielens and Hagen 1982). These calculations assumed the reaction $\mathrm{H}+\mathrm{HCO} \rightarrow \mathrm{H}_{2} \mathrm{CO}$, but ignored the $\mathrm{H}$ addition reaction to $\mathrm{H}_{2} \mathrm{CO}$ forming ultimately $\mathrm{CH}_{3} \mathrm{OH}$. If both these reactions take place on grain surfaces, then the calculated mixtures will have a 5-8 $\mu \mathrm{m}$ spectrum similar to that observed toward W33A (Tielens and Hagen 1982). Because of the ambiguity in the identification of the saturated hydrocarbon which produces the $6.8 \mu \mathrm{m}$ absorption in $\mathrm{W} 33 \mathrm{~A}$ and the uncertainties in the chemical reaction network and in the observed ratio of saturated hydrocarbons to $\mathrm{H}_{2} \mathrm{O}$, a more detailed comparison between the observations and the theoretical calculations is not warranted at present.

The simple grain surface chemistry described above may be able to explain the bulk of the grain mantle composition in W33A by accounting for most of the details in the spectrum. It is important to realize, however, that the complex mixtures, present in Mon R2-IRS2, BN, and NGC 2264, cannot be formed this way. Only in the unlikely event that the accretion rate of atomic carbon on grain surfaces is larger than that of atomic hydrogen and atomic oxygen together, can such complex molecules become important constituents of interstellar grain mantles through grain surface reactions. Theoretical calculations of interstellar chemistry suggest that this never occurs for typical conditions in molecular clouds (Prasad and Huntress 1980). The $610 \mu \mathrm{m}$ line of atomic carbon has been detected toward several molecular clouds (Phillips et al. 1981). It has been suggested that its strength implies that $\mathrm{C}_{\mathrm{I}}$ is as widespread and as abundant as $\mathrm{CO}$ in molecular clouds (Phillips and Huggins 1981). However, detailed calculations of the atomic photodissociation regions around $\mathrm{H}$ II regions or at the edge of molecular clouds, show that the $\mathrm{C}$ I probably arises 
in these regions and that the abundance of atomic carbon inside molecular clouds is probably low (Tielens and Hollenback 1984). It is extremely unlikely that molecular grain mantles are predominantly formed in these photodissociation regions. Furthermore, even if atomic carbon is more abundant than atomic hydrogen in the gas phase, it is expected that atomic oxygen has an even higher abundance, simply because $\mathrm{O}_{2}$ is more easily destroyed than CO. Grain surface reactions would then tend to form $\mathrm{CO}$ and $\mathrm{CO}_{2}$ rather than carbon chains. Finally, the presence of the $3.08 \mu \mathrm{m}$ ice band in these sources implies that $\mathrm{H}_{2} \mathrm{O}$ is an important constituent of accreted grain mantles. Because direct condensation of gas phase species on grain surfaces will never give rise to an $\mathrm{H}_{2} \mathrm{O}$ (and hydrocarbon) rich grain mantle, the $\mathrm{H}_{2} \mathrm{O}$ molecules have to be formed on the grain surface by reactions of atomic hydrogen with atomic or molecular oxygen (Tielens and Hagen 1982). This, in turn, implies that the $\mathrm{H}$ accretion rate is large, at least comparable to that of the heavier species. There seems therefore no way that grain surface reactions can explain the presence of a mixture of complex hydrocarbons in interstellar grain mantles.

The observation of broad absorption bands in the 5-8 $\mu \mathrm{m}$ region strongly argues for the occurrence of energetic processes which change the molecular composition of interstellar grain mantles. Greenberg and Yencha (1973) and Greenberg (1976) originally suggested that UV photolysis of grain mantles producing larger molecules could occur in the interstellar medium. This suggestion has been demonstrated by laboratory experiments on UV photolysis of mixtures of simple molecules (Hagen, Allamandola, and Greenberg 1979). The UV photolysis produces radicals, which can then react with their neighbors. Some of these radicals will be stored in the matrix at low temperatures $(10 \mathrm{~K})$. Figure 8 shows the $5-8 \mu \mathrm{m}$ spectra of two mixtures of simple molecules after irradiation with UV photons. The initial concentration of the different molecules is chosen in accordance with theoretical calculations, which include gas phase as well as grain surface chemistry (d'Hendecourt 1984). The infrared spectrum after irradiation shows the presence of many molecules which are not present before irradiation. Upon warm-up of these irradiated mixtures, further reactions can occur and simultaneously the more volatile molecules, such as $\mathrm{H}_{2} \mathrm{O}$, evaporate, leaving behind the complex molecules. Figure 8 also shows the spectra of the warmed-up mixtures (d'Hendecourt 1984). Obviously broad absorption features in the $5-8 \mu \mathrm{m}$ region can be produced by UV irradiation and warm-up of simple molecular mixtures.

While these results look very promising, more laboratory work is needed to study the chemistry and spectroscopy in more detail and to determine the uniqueness of the initial mixtures. It should be noted that there may be alternatives to UV photolysis. Such processing can work equally well when the radicals result from cosmic rays (Moore and Donn 1982; Pirronello et al. 1982; Strazzulla, Calcagno, and Foti 1983). It is important to note that the large molecules produced by these energetic processes are refractory and can more easily survive in the diffuse interstellar medium than accreted icy grain mantles. This lends some support to the possible presence of the broad and shallow absorption features in the spectrum of the galactic center. Obviously a 5-8 $\mu \mathrm{m}$ grating spectrometer spectrum of the galactic center is important to establish a possible link between grain mantles accreted in molecular clouds and their photoprocessed residues in the interstellar medium.

Finally we note that it is very well possible that photolyzed

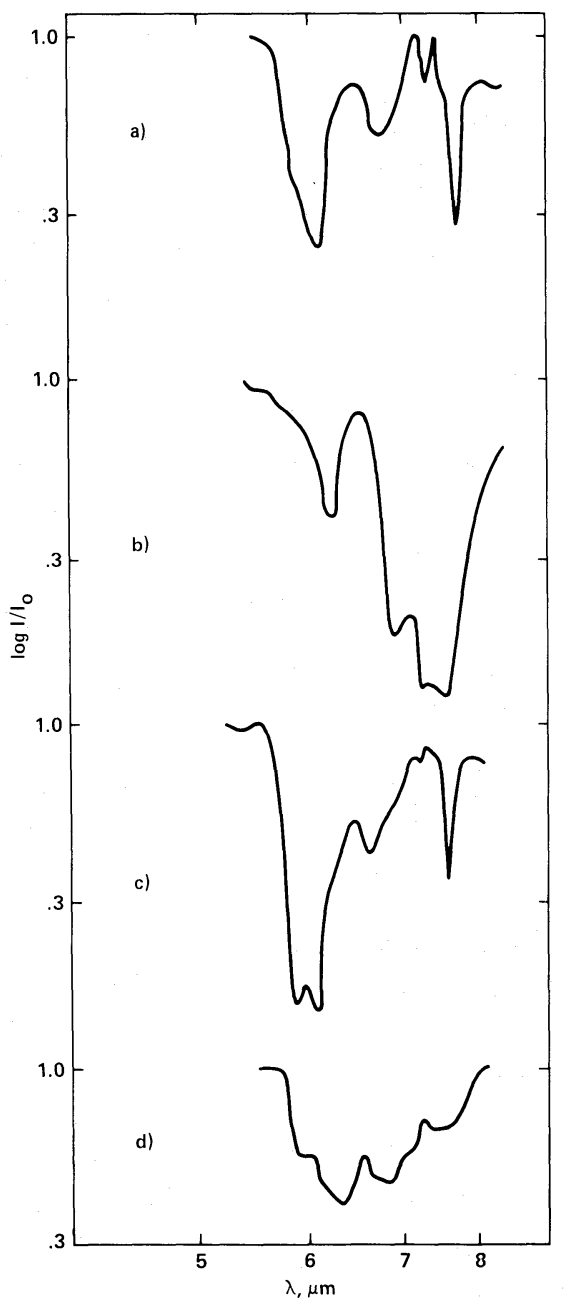

Fig. 8.-Laboratory spectra of an irradiated mixture of $\mathrm{H}_{2} \mathrm{O} / \mathrm{CO} / \mathrm{CH}_{4} / \mathrm{NH}_{3} / \mathrm{O}_{2} / \mathrm{N}_{2}(1 / 1 / 0.3 / 0.3 / 1 / 0.03)$ at $10 \mathrm{~K}(a)$ and at $230 \mathrm{~K}(b)$, and of an irradiated mixture of $\mathrm{H}_{2} \mathrm{O} / \mathrm{CO} / \mathrm{CH}_{4} / \mathrm{NH}_{3}(6 / 2 / 1 / 1)$ at $10 \mathrm{~K}(c)$ and at $230 \mathrm{~K}(d)$.

grain mantles are also present in $\mathrm{W} 33 \mathrm{~A}$. The $5-8 \mu \mathrm{m}$ spectrum of this source is dominated by the narrow and deep 6.0 and 6.8 $\mu \mathrm{m}$ absorption band, but the broad, shallow features may also be present underneath. In fact, the observation of an absorption band at $4.61 \mu \mathrm{m}$ in $\mathrm{W} 33 \mathrm{~A}$ has been interpreted as evidence for the presence of photolyzed mixtures in this source (Lacy et al. 1984). The column density of the species producing this absorption is, however, probably small compared to that of $\mathrm{H}_{2} \mathrm{O}$.

\section{SUMMARY}

The main results can be summarized as follows.

1. Spectra at $5-8 \mu \mathrm{m}$ are a valuable tool for the study of the molecular composition of interstellar grain mantles.

2. The shape of the observed 6.0 and $6.8 \mu \mathrm{m}$ features changes considerably from source to source. These differences are related to differences in the molecular composition of the grain mantle. The rather narrow 6.0 and $6.8 \mu \mathrm{m}$ bands observed in W33A are attributed to the $\mathrm{OH}$ bending mode in $\mathrm{H}_{2} \mathrm{O}$ and the $\mathrm{CH}$ deformation modes in saturated hydrocar- 
bons (for example, $\mathrm{CH}_{3} \mathrm{OH}$ ), accounting for about $30 \%$ of all the available carbon and oxygen. The larger width of the 6.0 and $6.8 \mu \mathrm{m}$ features in Mon R2-IRS2, BN, and NGC 2264 is probably due to the presence of a mixture of saturated and unsaturated hydrocarbons possibly containing strongly electronegative groups.

3. These differences in the composition of interstellar grain mantles cannot be explained by interstellar grain surface chemistry alone. Instead this probably implies that energetic processes, such as UV photolysis, are important for further modifying the composition of interstellar grain mantles. Laboratory studies support this suggestion.

4. A larger set of reliable 5-8 $\mu \mathrm{m}$ spectra of interstellar objects is needed to sort out interstellar grain chemistry. Of particular importance is confirming the presence of the broad and shallow 6.0 and $6.8 \mu \mathrm{m}$ band in the spectrum of the galactic center. Establishing a link between molecular grain mantles in dense interstellar clouds and the dust in the diffuse interstellar medium is of prime importance for our understanding of the evolution of interstellar dust.

\section{REFERENCES}

Allamandola, L. J. 1984, in Galactic and Extragalactic Infrared Spectroscopy, ed. M. F. Kessler and S. P. Phillips (Dordrecht: Reidel), p. 5.

Bellamy, L. J., 1960, The Infrared Spectra of Complex Molecules (London Methuen).

Bohlin, R. C., Savage, B. D., and Drake, J. F. 1978, Ap. J., 224, 132.

Capps, R. W., Gillett, F. C., and Knacke, R. 1978, Ap. J., 226, 863.

Cohen, M., Aitkin, D. K., Roche, P. F., and Williams, P. M. 1983, Ap. J., 273 624.

d'Hendecourt, L. 1984, Ph. D. thesis, University of Leiden, The Netherlands. Gillett, F. C., Jones, T. W., Merrill, K. M., and Stein, W. A. 1975, Astr. Ap., 45, 77.

Greenberg, J. M. 1976, Ap. Space Sci., 39, 9.

Greenberg, J. M., and Yencha, A. J. 1973, in IAU Symposium 52, Interstellar Dust and Related Topics, ed. J. M. Greenberg and H. C. van de Hulst (Dordrecht: Reidel), p. 369

Gribov, L. A., and Smirnov, V. N. 1962, Soviet Phys.-Uspekhi, 4, 919.

Hagen, W., Allamandola, L. J., and Greenberg, J. M. 1979, Ap. Space Sci., 65, 215

1980, Astr. Ap. 86, L3.

Hagen, W., and Tielens, A. G. G. M. 1981, J. Chem. Phys., 75, 4198.

. 1982, Spectrochim. Acta, 38A, 1089.

Hagen, W., Tielens, A. G. G. M., and Greenberg, J. M. 1981, Chem. Phys., 56,

369.

1983a, Astr. Ap. Suppl., 51, 389

1983b, Astr. Ap., 117, 132

Joyce, R. R., and Simon, T. 1982, Ap. J., 260, 604.

Khoshkhoo, H., and Nixon, E. R. 1973, Spectrochim. Acta., 29A, 603.

Kitta, K., and Kratschmer, W. 1983, Astr. Ap., 122, 105.

Knacke, R. F., McCorkle, S., Puetter, R. C., Erickson, E. F., and Kratschmer, W. 1982, Ap. J., 260, 141 .

Lacy, J. H., Baas, F., Allamandola, L. J., Persson, S. E., McGregor, P. J., Lonsdale, C. J., Geballe, T. R., and van de Bult, C. E. P. 1984, Ap. J., 276, 533.

Langer, W. D. 1976, Ap. J., 210, 328.
Merrill, K. M., Russell, R. W., and Soifer, B. T. 1976, Ap. J., 207, 763.

Moore, M. H., and Donn, B. 1982, Ap. J., 257, L47.

Nakagawa, N. 1980, in IAU Symposium 87, Interstellar Molecules, ed. B. H. Andrew (Dordrecht: Reidel), p. 365.

Nelander, B. 1980, J. Chem. Phys., 72, 77

Phillips, T. G., and Huggins, P. J. 1981, Ap. J., 251, 533.

Phillips, T. G., Huggins, P. J., Kuiper, T. B. H., and Miller, R. E. 1980, Ap. J. (Letters), 238, L103.

Pirronello, V., Brown, W. L., Lanzerotti, L. J., Marcantonio, K. J., and Simmons, E. H. 1982, Ap. J., 262, 636.

Prasad, S. S., and Huntress, W. T., Jr. 1980, Ap. J. Suppl., 43, 1.

Puetter, R. C., Russell, R. W., Soifer, B. T., and Willner, S. P. 1979, Ap. J., 228 118

Russell, R. W., Soifer, B. T., and Puetter, R. C. 1977, Astr. Ap., 54, 959

Soifer, B. T., Puetter, R. C., Russell, R. W., Willner, S. P., Harvey, P. M., and Gillett, F. C. 1979, Ap. J. (Letters), 232, L53.

Soifer, B. T., Willner, S. P., Capps, R. W., and Rudy, R. J. 1981, Ap. J., 250, 631.

Strazzulla, G., Calcagno, L., and Foti, G. 1983, M.N.R.A.S., 204, 59P.

Tielens, A. G. G. M. 1983, Astr. Ap., 119, 177.

. 1984, in Laboratory and Observational IR Spectra of Interstellar Dust, ed. R. Wolstencroft and J. M. Greenberg, p. 41.

Tielens, A. G. G. M., and Hagen, W. 1982, Astr. Ap., 114, 245.

Tielens, A. G. G. M., and Hollenbach, D. 1984, in preparation.

Tielens, A. G. G. M., Werner, M. W., and Capps, R. W. 1984, in preparation.

van der Zwet, G. 1984, private communications.

van IJzendoorn, L. J., Allamandola, L. J., Baas, F., and Greenberg, J. M. 1983 J. Chem. Phys., 78, 7019 .

van Thiel, M., Becker, E. D., and Pimentel, G. C. 1957, J. Chem. Phys., 27, 486

Werner, M. W., Dinerstein, H. L., and Capps, R. W. 1983, Ap. J., 265, 113.

Wilner, S. P., Russell, R. W., Puetter, R. C., Soifer, B. T., and Harvey, P. M. 1979, Ap. J. (Letters), 229, L65.

Willner, S. P., et al. 1982, Ap. J., 253, 174.

Witteborn, F. C., and Bregman, J. 1984, in preparation.

L. J. Allamandola, J. Bregman, J. Goebel, A. G. G. M. Tielens, and F. C. Witteborn: NASA/Ames Research Center, MS 245-6, Moffett Field, CA 94035

L. D’Hendecourt: Université de Paris VII, Groupe de physique des solides de L'E.N.SS., Tour 23-2, Place Jussieu, 75251 Paris cedex 05, France 